\title{
Saúde pública
}

\section{O sujeito entre a alcoolização e a cidadania: perspectiva clínica do trabalho}

\author{
Heliete Karam*
}

\section{INTRODUÇÃO}

Considera-se a construção do sujeito um processo contínuo, um processo que acompanha a pessoa durante toda a sua existência. Este processo não é inócuo, desprovido de reveses. Ao contrário, qualquer experiência pode ser bem aproveitada em favor desta construção. Todavia, dentro do quadro de referência teórico-metodológico da psicopatologia e psicodinâmica do trabalho, entendemos que o sujeito só acontece plenamente quando, através do trabalho ${ }_{a}$, a palavra psicológica de um indivíduo acede à palavra política ${ }^{1}$, isto é, quando o trabalho lança com sucesso este indivíduo, da esfera doméstica (oikos) à esfera pública (polis). Nossas pesquisas demonstraram que o fe-

Palestra realizada no VIII Colóquio Internacional de Sociologia Clínica e Psicossociologia: «Transformações Sociais. Subjetividades e Política». Belo Horizonte (MG), julho/2001 (texto revisado pela autora).

* Doutora em Psicologia Clínica e professora da UnB.

a Entendemos que trabalho «não é emprego, nem salário, nem tarefas e atividades, nenhuma das rotinas, nem o lugar da fábrica, o cumprimento de horários, a utilização dos instrumentos, nem as relações hierárquicas de poder ou o processo de produção. 0 trabalho não é. Há trabalho (real) quando é possível o investimento dos indivíduos na busca do acesso ao simbólico através do conjunto destes elementos constitutivos do cenário organizacional - o que requer a livre instituição das representações mentais, o jogo da partilha da palavra na instância do face a face e do olhar que significa o gesto de alguém (um) pela presença concreta do outro" (Karam, 1997), no sentido levinassiano de face e de olhar. nômeno da alcoolização em seu espectro patogênico surge como um sinal de bloqueio desta passagem - entrave ao mesmo tempo causa e efeito, à diferença de que, neste caso, a ordem dos fatores altera o produto: a alcoolização patogênica apresenta-se primeiro como efeito, para, a seguir, apresentar-se como causa desse impasse, cujo diagnóstico e superação compete aos profissionais de saúde mental.

Esta competência pode se efetivar, justamente, pelo uso de seu conhecimento e de suas habilidades na retomada do processo de construção do sujeito através da promoção da passagem da palavra psicológica à palavra política - fazer técnico-profissional que implica uma clínica do trabalho específica, a qual não se limita a reconhecer a centralidade ${ }_{b}$ do trabaIho como fator determinante para a retomada

\footnotetext{
b A psicologia do trabalho "descobriu estratégias coletivas de defesa, desconhecidas da psicanálise, que vão desempenhar um papel teórico maior na fundação de uma metapsicologia das articulações entre ordem singular e ordem coletiva, no seio da qual o trabalho ocupa um lugar de mediador, decisivo. Nesta perspectiva, a psicologia do trabalho não pode mais ser considerada como uma psicologia aplicada, nem como uma psicanálise aplicada. 0 trabalho torna-se um operador de inteligibilidade essencial para analisar as condutas humanas em geral e os processos implicados tanto na saúde mental como na doença. É o que visamos com a expressão centralidade do trabalho em psicologia. 0 trabalho não é um objeto particular entre outros tantos como a família, o lazer, [...] o esporte. Ele está colocado no próprio centro da psicologia, em condições de igualdade com a sexualidade.» (Dejours, 1996).
} 
do referido processo, mas, além deste reconhecimento, também investe no trabalho como operador de saúde mental através da promoção da cidadania no próprio local de trabalho, pois ninguém é mais ou menos cidadão: a cidadania é algo pleno, exercido em qualquer lugar e em tempo integral, inclusive nas empresas, admitindo-se, portanto, conforme assinala Ives Clot, $1996_{c}$, que «o trabalho encontra-se no registro do ser, e não apenas no registro do consumo».

\section{POR UMA CLÍNICA PSICOPOLÍTICA DAS ALCOOLIZAÇÕES}

Partimos, aqui, de uma determinada noção de clínica ${ }_{d}$ : aquela que recupera o sentido deste vocábulo em sua origem, traduzindo a presença do médico à cabeceira do leito de seu paciente. No caso, os pesquisadores, ou meIhor, os clínicos do trabalho vão ao encontro do sujeito em situação de sofrimento - analogia que diz respeito, portanto, à topografia dos lugares onde realizamos nossa ação-pesquisa; Salmona, $1992_{\mathrm{e}}$, porquanto partimos de um determinado território (ibidem; 1992), nele a desenvolvemos, e a ele voltamos de maneira constante. Quando nosso objeto for o sujeito em situação de sofrimento (mental) no trabalho, nos referimos a «uma clínica do trabalho e da ação »², a uma forma de psicologia concreta no sentido dado a esta expressão por Politzer, 1928 e que, como sugere ${ }^{2}$, pode ser entendida como uma psicologia da ação - psicologia que, no curso da história das idéias f filia-se à tradição compreensiva inaugurada pela interlocução entre Dilthey (1833-1911) e Durkheim (1858-1917) a respeito da validação das pesquisas em ciências humanas.

Foi a partir destas bases que confirmamos a importância de se demarcar a diferença entre os conceitos de alcoolismo e de alcoolização, e que sistematizamos uma maneira específica (1979-2003) de abordar o fenômeno da embriaguez em sua relação com o trabalho (e o não/ trabalho) - maneira que denominamos clínica

c Conforme as colaborações de Ives Clot, nas reuniões do Laboratório de Psicologia do Trabalho do Conservatório Nacional de Artes e Ofícios (CNAM) de Paris. Ives Clot é filósofo e integra a equipe de pesquisadores deste Laboratório.

¿Esta noção é comum à Psicossociologia, à Sociologia Clínica e à Psicopatologia e Psicodinâmica do Trabalho.

e Cf. Salmona, M., em reuniões no Laboratório de Psicologia do Trabalho do Conservatório Nacional de Artes e Ofícios de Paris/CNAM, no período 1992-97. Michèle Salmona é antropóloga.

fCf. Ch. Dejours. "Psychologie clinique du travail et tradition compréhensive». Paris, 1996 (mimeo; pp. 1-2). 0 autor assinala que concebe esta herança de forma absolutamente profana, isto é, sem seguir nenhum método específico de análise e de exposição. psicopolítica das alcoolizações e, para além do álcool, também das demais formas de adicção massiva, abusiva e banalizada a outras substâncias psicoativas ${ }^{1}$.

\section{1) Alcoolismo e alcoolização}

Sem dúvida, o alcoolismo é um comportamento objetivo bastante estudado e hoje se dispõe de uma vasta bibliografia a respeito, na qual nos deparamos com os mais variados esforços de busca conceitual. Todavia, a dificuldade de circunscrevê-lo enquanto conceito médico de enfermidade permanece: se, conforme desafia Bertolote ${ }^{7}$, tivermos paciência para examinar os mais de mil itens da Classificação Internacional de Doenças (CID), constataremos que é impossível localizar uma definição de alcoolismo propriamente dito, apesar das várias rubricas nela encontradas, referentes aos efeitos do álcool sobre o organismo humano. Ao que parece, segundo Bertolote (ibidem), o delirium tremens continua sendo a única forma clínica indiscutível de alcoolismo. Enquanto delírio alcoólico agudo, ele constitui a forma mais grave da síndrome de abstinência, no caso entendida como o conjunto de sinais patológicos que sobrevêm ao indivíduo logo que o mesmo interrompe seu consumo de etanol. Assim, apenas assinalamos que, entre as várias tentativas de definição de alcoolismo encontradas na literatura, sintonizamos com a de $P$. Fouquet (anos 50), a qual considera o alcoolismo a perda total de liberdade face ao álcool - perda atribuída à necessidade estritamente orgânica de manter um determinado teor de etanol no corpo, com vistas a restabelecer seu equilíbrio neurovegetativo, salvaguardando uma aparente sensação de conforto físico e de bem-estar psíquico.

A alcoolizaçãog, por sua vez, é o ato de alcoolizar algo ou alguém, ou seja, o ato de injetar álcool num determinado corpo - o que, no caso do consumo humano, significa que todo o alcoólico se alcooliza, mas que nem todo aquele que se alcooliza é um alcoólico. Esta diferença parece óbvia; mas, para a prática dos profissionais do campo da saúde mental e trabalho, sua precisão é relevante para orientar as abordagens individualizadas, de grupo ou de âmbito organizacional/institucional. Ao estudarmos as condutas de alcoolização no contexto do trabalho durante mais de vinte anos, não só pudemos confirmar concretamente a relevância

g Cf. Haut Comité d'Étude et d'Information sur l'Alcoolisme. Dictionnaire d'Alcoologie. La Documentation Française, Paris, 1987 (p. 16). 
desta diferença diagnóstica, como, também, e principalmente, constatamos um conjunto de particularidades no interior deste fenômeno muitas vezes banalizado. A título de colaboração para com os debates na área, citamos, a seguir, algumas das principais particularidades encontradas, pois entendemos que um equívoco diagnóstico pode incorrer no risco de mal/ tratarmos um problema atual tão grave como o do consumo abusivo de álcool (e de outras substâncias psicoativas):

a) O caráter massivo do ato de se alcoolizar, sem que os alcoolizados - mesmo que contumazes e apresentando alterações orgânicas (GGT elevada) e/ou de comportamento (acidentes de trabalho e de percurso) - pudessem ser diagnosticados como portadores da síndrome alcoolismo. Além de se diferenciar do alcoolismo propriamente dito, esta forma de alcoolização diferenciava-se, também, das alcoolizações genuinamente festivas;

b) Sua etiologia não orientava em direção à doença, mas ao sofrimento mental daqueles trabalhadores cuja continuidade do processo de construção da identidade, através do ingresso na esfera pública pela via do trabalho, achava-se seriamente ameaçada devido à suspensão de sua palavra;

c) A suspensão da palavra no ambiente de trabalho $o_{h}$ era fruto do uso do constrangimento, da intimidação e do medo como ferramentas gerenciais - o que obrigava os coletivos de trabalho a investirem sua inteligência na busca permanente de um estado de equilíbrio entre a realização das atividades e tarefas e a impossibilidade de elaboração do sofrimento, pois esta elaboração dependia da circulação da palavra dentro da empresa, relacionada ao fazer próprio de cada trabalhador e à interface de uns com os outros;

d) Por ser relativamente barato, socialmente aceito, e por permitir o alívio imediato da tensão decorrente dessa situação, o álcool era a substância química eleita pelos trabalhadores para aplacar o sofrimento mental indizível decorrente da suspensão da palavra. Sua ingestão revelou-se uma prática de controle imposta pelo(s) coletivo(s) aos seus integrantes, fornecendo-lhes a sensação de pertencimento, proteção, coesão do grupo e reconhecimento prática a não ser confundida com solidariedade, conforme alerta a corrente francesa de estudos sobre álcool e trabalho;

e) O tipo de alcoolização identificada tinha

Quando nos referimos a trabalho, incluímos, necessariamente, o nãotrabalho. uma função defensiva bastante precisa, instituindo uma forma coletiva de administração do dito sofrimento mental - forma utilizada por homens e mulheres, ainda que diferentemente ${ }_{i}$;

f) Esta defesa do coletivo permita que os trabalhadores conseguissem suportar o sofrimento psíquico, sem darem mostras evidentes de descompensação, bem de acordo com o quadro que McDougall ${ }^{3}$ denomina "normopatia";

g) Mas, mais do que apenas uma entre as várias possíveis estratégias coletivas de defesa (Ch. Dejours, 1980), esta alcoolização específica, ao descobrirmos que havia sido guindada ao status de valor pelo conjunto dos trabalhadores estudado (dimensão axiológica da gestão operária do sofrimento), revelou-se uma verdadeira ideologia de resistência (Dessors, 1997) j imposta aos indivíduos, encerrando uma dramaturgia operária própria ainda pouco estudada e "rebelde", isto é, incapaz de ser "tratada" através dos modelos clássicos de tratamento e prevenção do uso abusivo de álcool e outras drogas - modelos limitados à esfera doméstica do problema, modelos que, neste caso, não levam em conta a primazia da dimensão pública, ou melhor, da dimensão política em seu sentido pleno, sobre o caráter hegemônico das abordagens tradicionais;

h) Nossas pesquisas confirmaram ainda que:

- se o trabalho, enquanto «objeto carrefour do simbólico» Revuz, 1996, for colocado no centro das discussões sobre o consumo abusivo de álcool, isto é, se for reconhecido, na prática, como operador da palavra, ele é capaz de transformar o quadro exposto; mas isto, à condição de que ele seja, realmente, o operador efetivo deste movimento, que consiste da instauração de um processo que, no seio das empresas e mediante um fazer próprio, invista na substituição do álcool pela palavra política dos trabalhadores em todos os escalões e de forma intersubjetiva;

- a interpretação da gestão do sofrimento mental no trabalho, pelos próprios coletivos e através da intermediação dos clínicos do traba-

¡Não discutiremos aqui a vertente que abre em direção às questões de gênero.

¡Cf. Dominique Dessors, por ocasião do I Colóquio Internacional de Psicodinâmica e Psicopatologia do Trabalho (Paris, 30-31/01/1997), retomando sua discussão com $\mathrm{Ch}$. Dejours a respeito de um dos conceitos fundadores da Psicopatologia e Psicodinâmica do Trabalho.

Cf. Revuz, C. "Sujet et Subjectivité». Comunicação feita na reunião de 22.11.1996, no Laboratório de Psicologia do Trabalho do Conservatório Nacional de Artes e Ofícios (CNAM) de Paris. Christine Revuz é psicanalista e integra a equipe de pesquisadores deste Laboratório. 
Iho, ajuda na ruptura com o patogênico e no acesso à criação de uma outra forma de se estar juntos (no sentido arendtiano do termo), que não seja pela alcoolização enquanto ideologia defensiva ${ }^{1}$.

\section{2) Mas por que essa alcoolização específica preocupa e o que fazer?}

Quanto menos a palavra política circular num determinado coletivo ou sociedade, mais seus integrantes tendem a se alcoolizar ou a se drogar. O problema reside em que, misturada a outras formas de alcoolização, ou seja, não isolada e não reconhecida nas particularidades aqui expostas, a alcoolização patogênica acaba sendo confundida e abordada inadequadamente, muitas vezes trazendo à equipe terapêutica uma sensação de fracasso ${ }_{m}$, bem como aos familiares dos supostos pacientes, ou causando outro tipo de sofrimento àquele que aceita ou se submete a tratamento convencional para alcoolismon.

Ora, se o alcoolismo propriamente dito demanda uma abordagem individualizada, e até mesmo singularizada ${ }^{5}$, a alcoolização massiva enquanto ideologia de resistência, ao contrário, demanda um trabalho clínico coletivo e intersubjetivo de inteligibilidade do sofrimento mental em sua relação com o trabalho. Todavia, considerando que este sofrimento constitui-se como tal justamente por ser indizível, o primeiro passo consiste, então, da restauração da palavra das empresas. Não nos referimos à palavra terapêutica nem aos "programas participativos" tão em voga, mas a um trabalho que tem lugar lá onde a psicologia interage com a sociologia da ética. Isto, porque o recurso à ideologia de resistência como defesa contra o sofrimento denota a presença do medo decorrente da desconfiança, esta empiricamente bem conhecida da psicologia e da psiquiatria porque «está no centro de numerosas doenças mentais» ${ }^{6}$. No entanto, embora pareça natural procurar-se nestas duas áreas os elementos constitutivos da confiança enquanto instrumento de reversibilidade da desconfiança patogênica ou patológica, «tal busca revelou-se decepcionante e foi necessário admitir que a confiança, como conceito, não provém da psicologia», isto é: «a confiança não repousa sobre habilidades psi-

m Justamente porque há uma confrontação com o real do trabalho, isto é, com 0 que escapa a sua prescrição.

n Aquele tratamento centrado no indivíduo, mesmo que aberto à participação de familiares, chefias e colegas. cológicas, mas sobre habilidades éticas ${ }^{6}{ }_{0}-$ razão pela qual advogamos em favor de uma clínica do sofrimento no ambiente de trabalho, como recurso profissional prioritário em relação à clínica das manifestações patológicas orgânicas ou de comportamento. De fato, a clínica do trabalho a qual nos referimos focaliza a questão do sofrimento mental por entender que este é um fenômeno que antecede à formação de sintomas. Mas quais são as habilidades éticas constitutivas desta clínica?

A questão de fundo é a da liberdade, contrapondo sofrimento e cidadania. Se a palavra está em sofrimento, a cidadania está em perigo. Esta depende das condições em que a palavra encontra-se em sofrimento num determinado coletivo, e das chances de se lidar com este sofrimento. É preciso dizer que, reconhecendoo como inerente à condição humana, à condição de se estar (irremediavelmente) sujeito $a_{\mathrm{p}}$, Dejours e Abdoucheli (1990) isolam, para fins de entendimento, dois tipos de sofrimento: o sofrimento patogênico (capaz de degenerar em sofrimento patológico e, até mesmo, de se tornar crônico, instaurando um circuito repetitivo de adoecimentos de toda ordem, como por exemplo, os casos de L.E.R./D.O.R.T.q) e o sofrimento criador (aquele capaz de transformar criativamente o patogênico, antes que este se torne patológico e passe a se manifestar pela linguagem da dor).

\section{SOFRIMENTO E CIDADANIA}

Entendemos que a questão do sofrimento traz consigo a idéia de gestão do sofrimento. Segundo os autores citados anteriormente, a qualidade da saúde mental de cada pessoa, e mesmo de saúde física (terreno da psicossomática), é em grande parte determinada pela maneira como o indivíduo, buscando se manter em equilíbrio (saúde), consegue suportar as frustrações com as quais vai se deparar na passagem do singular para o plural por ocasião do confronto com a realidade do mundo do trabalho - realidade externa a sua subjetividade. Tudo depende de como cada pessoa "negocia" seu desejo com esta realidade, cujas regras já estão definidas antes mesmo que nela desembarque com sua história particular. De

\footnotetext{
0 Dejours, Ch. Le facteur humain. PUF (Col. Que sais-je?); Paris, 1995 (pp. 59-60).

p Submetido às intempéries, à fragilidade, à incompletude, à vida, à morte, ao outro, ao absurdo da existência no sentido sartriano da expressão.

q Respectivamente, lesões por esforço repetitivo e doenças osteoarticulares relacionadas ao trabalho.
} 
fato, o sofrimento é sempre uma experiência individual; não existe sofrimento coletivo. O que pertence ao coletivo é a gestão do sofrimento o que se dá através da construção inconsciente de estratégias defensivas por parte de um conjunto de trabalhadores, conforme assinalam os estudos de Ch. Dejours (passim).

É neste quadro que entra nossa interpretação do consumo de álcool em questão. Há uma violência estrutural na base deste consumo, capaz de gerar a violência quotidiana, , na medida em que os conflitos próprios às relações de poder não se solucionam, mas se cristalizam, metamorfoseando-se em queixas, adoecimentos, acidentes ou quase acidentes, suicídios ou tentativas de suicídio, criminalidade e tantas outras formas de sintomas sociais, sintomas que, pelas razões expostas, denominamos de psicopolíticos ${ }^{1}$. Trata-se de uma espécie de sofrimento mal sucedido, isto é, de um sofrimento patogênico que, não conseguindo aceder a sofrimento criador, decompõe-se em diferentes formas de expressão da dor, cujas causas não se restringem tão somente ao âmbito íntimo das relações objetais, ou ao âmbito doméstico do romance e dos segredos familiares. Se o trabalho é o operador do movimento em direção à construção do "sujeito social|»" à construção do cidadão, a palavra é sua alavanca. É ela que desencadeia e dá sustentação à clínica proposta, instituindo um trabalho de palavra, uma espécie de perlaboraçãos coletiva das defesas colocadas em ato pelos conjuntos de trabalhadores afetados de forma patogênica pelo sofrimento indizível.

Mas a circulação da palavra não assegura que ela seja livre, sobretudo quando está submetida a uma ou mais ideologias. Há que se fazer circular a palavra e logo investir na sua inteligibilidade através da instauração do «espaço de discussão», Habermas, 1989 - conceito assim integrado à psicopatologia e psicodinâmica do trabalho: «um espaço onde podem ser formuladas livremente e, sobretudo publicamente, as opiniões eventualmente contraditórias, em vista de proceder a arbitragens e de tomar decisões sobre as questões que interessam o futuro do serviço, do departamento, da empresa ou da instituição e que, portanto, também dizem respeito ao futuro concreto de todos

Expressões de Alexandre Dorna, cf. resumo de: «Los aportes de la psicología política al debate sobre la ausencia de proyetos políticos y la crisis de las ciencias sociales". Texto apresentado no Congresso Mundial de Psicologia Política. México, jul/ag. 2001

${ }_{s}$ Descrita pela psicanálise como o processo pelo qual o analisando integra os membros que os constituem ${ }^{6}$. Este recurso comprovou-se uma clínica do trabalho eficaz, removendo a alcoolização da vida dos indivíduos na medida em que estes, pelo efetivo exercício da cidadania no trabalho, se inseriram singular e definitivamente na vida comunitária : o consumo massivo de álcool se reduzia significativamente na proporção exata em que cada vez mais pessoas se davam como objetivo comum, a transformação do local de trabaIho em espaço de discussão. É aqui que o sujeito se consolidava como tal, ao compreender que sua razão de ser no mundo não se esgotava no nível da subjetividade ${ }_{u}$, mas se estendia ao âmbito da intersubjetividade, onde sua singularidade tinha papel determinante para o conjunto (dimensão política da interface palavra e trabalho).

Esse movimento, sem dúvida, exige uma concepção ética do sofrimento que permita articular, de forma harmônica e discordante, os singulares e o plural - movimento a ter lugar na instância do nós, lá onde se confrontam os valores do espaço íntimo e doméstico com os valores do espaço público ou político. Ao contribuir para a construção social através do trabaIho de palavra, o sujeito recebe uma retribuição moral/simbólica ${ }^{6}$ que the possibilita um nome próprio, um reconhecimento por parte do outro, do diferente/semelhante (seus pares, seus superiores ou subordinados hierárquicos, a sociedade), um espaço de jogo $\mathrm{v}_{v}$ construtor da alteridade/identidade. O descarte da palavra de uns por parte de outros bloqueia essa transação, esse comércio entre o eu-tu (esfera doméstica) e o nós (esfera pública).

A descartabilidade da palavra operária interrompe o curso desses processos individuais, pois, ao suspender a possibilidade de cada pessoa significar no coletivo o seu fazer, o seu gesto, o seu ato transformador da matéria, tal descartabilidade, suspende, ao mesmo tempo, e em decorrência, o trabalho de se significar no mundo. Ocupar a boca, e até mesmo todo aparelho fonador, com o álcool em vez da palavra, não deixa de ser uma forma de injetar linguagem lá onde a palavra não circula (Mijolla e Shentoub, 1990). Assim, o recurso a adicção, abdicando da dicção, isto é, a «afasia operária» 1 , surge, então, como uma forma de regres-

\footnotetext{
t Não nos referimos ao "trabalho voluntário".

"Entendemos por subjetividade "as fantasias, a imaginação, a criatividade, 0 desejo do sujeito e sua afetividade até o nível das pulsões, mas, também, toda a gama de valores próprios a esse sujeito, ou seja, a componente axiológica, fruto da cultura" (Karam, 1997).

v Entendemos que o espaço de discussão, em Habermas (1989), seria uma espécie de espaço transicional (Winnicott, 1951) da vida adulta.
} 
so a fases anteriores do desenvolvimento para fins de administração e sedação do sofrimento. É quando os fatores patogênicos correm o risco de encaminharem para as patologias, obrigando os profissionais da saúde a centrarem esforços na intervenção sobre as doenças, em detrimento do investimento em ações ético-políticas, voltadas para uma abordagem compreensiva do sofrimento humano em sua relação com o trabalho - vetor pelo qual entendemos a construção da cidadania.

\section{CONCLUSÃO}

Apesar do investimento na luta pela cidadania, as sociedades atuais enfrentam um estado de sofrimento inédito, o qual induz a um tipo de acordo tácito: a cultura da competitividade (narcísica, ego/ista), e não da cooperação (social/ista), vem empurrando os indivíduos, de forma massiva e subliminar, para o que TibonCornillot $^{10}$ denomina o «enquadramento neuroquímico das populações" - fenômeno que este autor denuncia como resultante da aliança entre o Estado, a polícia e os profissionais de saúde.

Face a esta espécie de embriaguez social, a cidadania configura-se como uma idéia frágil, pois exatamente como no alcoolismo, constatase a perda de liberdade face à substância química eleita para sedar o sofrimento por motivos bem mais complexos do que os orgânicos: nossas pesquisas demonstraram que o álcool (e recursos semelhantes) é proposto pelos excludentes aos excluídos da palavra, e que, sem margem de negociação, os coletivos excluídos adotam tal proposição impondo-a aos seus integrantes. Mas, ainda assim, consideramos a cidadania uma construção psicopolítica ${ }^{1}$ possível, desde que implique uma ação de reciprocidade exercida no âmbito da consciência e da responsabilidade plural, ou no âmbito do que Paul Ladrière ${ }^{11}$, com base na obra de Paul Ricœur (passim), denomina uma ética da mutualidade. Seu exercício no interior das empresas é o escopo no qual concebemos uma determinada clínica do trabalho.

\section{REFERÊNCIAS BIBLIOGRÁFICAS}

1. Karam HMC. Travail, Souffrance, Silence. Analyse psychodynamique et nouvelles orientations thérapeutiques de l'alcoolisme. Tese de doutorado em Psicologia Clínica. Paris, 1997.

2. Dejours Ch. "Psychologie clinique du travail et tradition compréhensive". Paris, 1996 (37 pp.).
3. McDougall J. Em defesa de uma certa anormalidade. Teoria e Clínica psicanalítica. Artes Médicas, 4aㅡ ed., Porto Alegre, 1991.

4. Barus-Michel J. Le sujet social. Étude de psychologie sociale clinique. Dunod, Paris, 1987.

5. Edwards G. The treatment of drinking problems. Grant McIntyre, London, 1982.

6. Dejours Ch. Le facteur humain. PUF (Col. Que sais-je ?), Paris, 1995.

7. Bertolote M. "Conceitos em alcoolismo". In: Ramos SP e col. Alcoolismo Hoje. Artes Médicas, Porto Alegre, 1987 (pp. 11-18).

8. Dejours Ch. et Abdoucheli E. "Itinéraire théorique en psychopathologie du travail". Revue PRÉVENIR, "Travail et santé mentale", n²0,1e. semestre; Paris, 1990 (pp. 127-147).

9. Mijolla A. et Shentoub SA. (1973) Pour une analyse de l'alcoolisme. Payot, Paris, 1990.

10. Tibon-Cornillot M. "Destin de la toxicomanie. Remarques à propos des iatrogénèses épidémiques et de l'encadrement neurochimique des populations". In: Interventions, $n^{\circ} 50$, juillet 1995 (pp. 38-43).

11. Ladrière P. e Gruson $C$. Éthique et gouvernabilité. PUF, Paris, 1992.

\section{FONTES DE CONSULTA}

1. Anouilh J. (1946) Antigone. La Table Ronde, Paris, 1996.

2. Arendt $\mathrm{H}$. Condition de l'homme moderne. Calmann-Lévy, Paris, 1961.

3. Bailhache G. Le sujet chez Emmanuel Lévinas. Fragilité et subjectivité. PUF, Paris, 1994.

4. Buber M. (1923) Je et Tu. Aubier. Paris, 1969.

5. Dorna A. "Los aportes de la psicología política al debate sobre la ausencia de proyetos políticos y la crisis de las ciencias sociales". Congresso Mundial de Psicologia Política. México, jul/ag. 2001.

6. Habermas J. De l'Éthique de la discussion. Cerf, Paris, 1992.

7. (1962) L'Espace public. Payot, Paris, 1992.

8. Haut Comité d'Étude et d'Information sur l'Alcoolisme. Dictionnaire d'Alcoologie. La Documentation Française, Paris, 1987.

9. Karam HMC. "Alcool et Violence". 2ème Colloque International de Psychodynamique et Psychopathologie du Travail: Violence et Travail. CNAM/Revue Travailler. Paris, 12/03/1999 (pp. 53-60).

10. "Trabalho e Saúde Mental: da resistência à criação". Revista Expressão Psi. V. 3, № 2, Dez/1999. Escola de Psicologia. EDUCAT, Pelotas (RS); (pp. 65-79).

11. "Álcool e violência". Texto revisado e traduzido para o português pela autora, publicado na Revista Expressão Psi. V. 4, № 1, jan.-jun./2000. Escola de Psicologia. EDUCAT, Pelotas (pp. 07-16).

12. Laplanche J e Pontalis J-B. (dir. de Lagache D.) (1967). Vocabulaire de la psychanalyse. PUF, 10 ed., Paris, 1990.

13. Levinas E. Entre nous. Le Livre de Poche, Paris, 1991.

14. _ Éthique et Infini. Le Livre de Poche, Paris, 1982.

15. Humanisme de l'autre homme. Le Livre de Poche, Fata Morgana, 1972.

16. McDougall J. Teatros do corpo. O psicossoma em psicanálise. Martins Fontes, São Paulo, 1991.

17. Teatros do eu. Ilusão e verdade no palco psicanalítico. Francisco Alves, 
18. Politzer G. (1928). Critique des fondéments de la Psychologie. PUF, Paris, 1974.

19. Vasse D. "Entre o gosto das coisas e o peso das palavras. O mal-entendido do medo". In: Joyce McDougall et alii. O Divã de Procusto. Artes Médicas, Porto Alegre, 1991 (pp.29-44).

20. Winnicott DW. (1971) Jeu et réalité. L'espace potentiel. Gallimard, Paris, 1994

\section{RESUMO}

Este artigo focaliza a importância da centralidade do trabalho para que o sujeito, na fase adulta, não interrompa seu processo de construção da identidade ao ingressar no âmbito do espaço público - interrupção que gera sofrimento e, com o tempo, tende a gerar, também, uma gama de sintomas psicológicos, sociais e, muitas vezes, orgânicos. Quando o trabaIho perde esta centralidade, ou seja, quando falha como operador de saúde mental, as práticas de alcoolização massiva e abusiva, muitas vezes confundidas com alcoolismo, podem se instalar enquanto estratégias coletivas de defesa contra o sofrimento patogênico. Uma certa forma de se trabalhar coletivamente com os trabalhadores sobre o sentido de suas atividades e tarefas numa determinada organização mostrou-se capaz de reverter este quadro, na medida em que substituiu o álcool pela palavra.

Descritores: Saúde mental e trabalho, psicopatologia do trabalho, psicodinâmica do trabalho, alcoolismo, estratégias coletivas de defesa, cidadania, psicologia do trabalho.

\section{ABSTRACT}

This article focuses on the importance of the centrality of work so that the subject, in the adult phase, does not interrupt his process of constructing an identity by entering the public sphere - an interruption which generates suffering and over time tends also to generate a wide range of psychological, social and, in many cases, organic symptoms. When work no longer is central, i.e., when it fails as an operator of mental health, the massive and abusive practices of "alcoholization", often confused with alcoholism, can be used as a collective defensive strategy against pathogenic suffering. A certain way of working collectively with workers concerning the sense of their activities and tasks in a particular organization proved capable of turning around this picture, insofar as it replaced alcohol by the word.

Key-words: Mental health and work, the psychopathology of work, the psychodynamics of work, alcoholism, collective defensive strategies, citizenship, psychology of work.

Title: The subject between alcoholization and citizenship: clinical perspective of work

\section{RESUMEN}

Este artículo foca la importancia de la centralidad del trabajo para que el sujeto, en la fase adulta, no interrumpa su proceso de construcción de la identidad al ingresar en el ámbito del espacio público interrupción que genera sufrimiento y, con el tiempo, tiende a generar, también, una gama de síntomas psicológicos, sociales $y$, muchas veces, orgánicos. Cuando el trabajo pierde esta centralidad, o sea, cuando falla como operador de salud mental, las prácticas de alcoholización masiva y abusiva, muchas veces confundidas con alcoholismo, pueden instalarse como estrategias colectivas de defensa contra el sufrimiento patogénico. Una cierta forma de trabajar colectivamente con los trabajadores sobre el sentido de sus actividades y tareas en una determinada organización se mostró capaz de reverter este cuadro, en la medida que sustituyó el alcohol por la palabra.

Palabras-clave: Salud mental y trabajo, sicopatología del trabajo, psicodinámica del trabajo, estrategias colectivas de defensa, ciudadanía, sicología del trabajo.

Título: El sujeto entre la alcoholización y la ciudadanía: perspectiva clínica del trabajo

Endereço para correspondência:

Heliete Karam

SQN 407 - Bloco A Ap. 311 - Asa Norte

70855-010 - Brasília - DF

E-mail: hkaram@terra.com.br

Copyright () Revista de Psiquiatria

do Rio Grande do Sul - SPRS 